\title{
Geologia
}

\section{Investigação Gravimétrica do Complexo Alcalino de Ipanema, São Paulo, Brasil}

\author{
André Rugenski (andrerug@iag.usp.br), Marta Silvia Maria Mantovani, Wladimir Shukowsky \\ Instituto de Astronomia, Geofísica e Ciências Atmosféricas - USP \\ R. do Matão 1226, CEP 05508-090, São Paulo, SP, BRA
}

Recebido em 02 de fevereiro de 2006; aceito em 05 de maio de 2006

Palavras-chave: Complexo Alcalino de Ipanema, Geofísica, gravimetria.

\section{RESUMO}

O Complexo Alcalino de Ipanema localizado na província alcalina de mesmo nome $\left(23^{\circ} 27,5^{\prime} \mathrm{S}\right.$ e $\left.47^{\circ} 38^{\prime} \mathrm{W}\right)$ dista aproximadamente 140 km de São Paulo, e há 40 anos foi tema de estudo geofísico em programa de Doutorado. Os métodos empregados foram o gravimétrico, o magnetométrico, e o eletrorresistivimétrico (SEV). Entretanto, os dados gravimétricos então levantados não foram referenciados à Rede Gravimétrica Fundamental Brasileira, nem à Rede de Nivelamento do IBGE, o que impossibilita sua integração e utilização com outros bancos de dados. Optou-se, então, por efetuar um novo levantamento na área e adjacências, de forma a integrá-lo aos dados de levantamentos geofísicos próximos referidos às duas redes citadas, uma vez que o complexo alcalino em questão é parte de um estudo integrado desses corpos na região S-SE do Brasil. O presente estudo concentra-se no método gravimétrico, tendo como resultados a geometria do corpo em subsuperfície bem como o cálculo de seu volume.

Keywords: Ipanema Alkaline Complex, Geophysics, gravimetry.

\section{ABSTRACT}

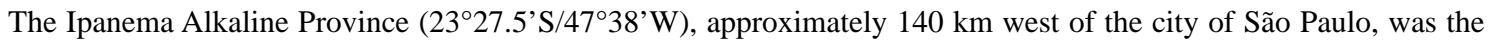
subject of a previous doctoral study employing geophysical (gravimetry, magnetics and electro-resistivity) methodologies. The gravimetric data, however, were neither referred to the Fundamental Brazilian Gravimetric Network (ON) nor to the Brazilian Reference Leveling Network (IBGE), thus preventing their integration with other data bases. As this alkaline complex is one of a number of such bodies presently under analysis in S-SE Brazil, new gravimetric data were obtained in the same and neighboring areas for integration with other geophysical surveys referred to both networks. The present study determined the geometry and volume of the buried body using solely on the basis of the gravimetric method. 


\section{INTRODUÇÃO}

O presente trabalho constitui parte de um projeto mais amplo que integra o estudo das principais manifestações alcalinas da região S-SE do Brasil. Alguns complexos do conjunto selecionado já foram detalhados quanto a sua geometria em subsuperfície com o intuito de verificar a existência de correlação entre a forma de alojamento e a tectônica que atuou no processo geológico que os originou (Slavec et al., 2001 e 2004; Rugenski et al., 2001 e 2005; Mantovani et al., 1999 e 2005).

O Complexo Alcalino de Ipanema, localizado na província alcalina de mesmo nome, aproximadamente a $140 \mathrm{~km}$ a oeste da cidade de São Paulo, (2327,5' S e 47³8' W), foi estudado com a utilização de métodos geofísicos, pela primeira vez, por Davino (1965). Os métodos então empregados foram os potenciais (gravimetria e magnetometria) e a eletrorresistividade com a técnica de sondagem elétrica vertical (SEV).

Devido à natureza dos métodos potenciais, que permite:

1. discriminar no espectro de freqüência as componentes das fontes localizadas em diferentes profundidades e, portanto, separá-las;

2. analisar o sinal de cada componente sobre uma superfície e não apenas ao longo de perfis e, finalmente,

3. delimitar lateralmente a fonte causadora da anomalia, desde que exista um contraste de densidade e/ou susceptibilidade magnética mensuráveis entre a fonte e a rocha encaixante, os torna mais adequados para a investigação das intrusões magmáticas, mesmo se comparados aos métodos sísmicos (Vigneresse, 1995).

Para realizar uma modelagem da geometria em subsuperfície do corpo que aflora, os dados gravimétricos descritos por Davino (1965) necessitavam de maior detalhamento, em particular para o cálculo do campo regional. Além disso, as medidas gravimétricas então levantadas utilizaram um gravímetro do tipo Nörgaard que, comparativamente ao LaCoste e Romberg, (modelo G) empregado neste trabalho, apresenta acurácia muito inferior. Ainda, no citado trabalho pioneiro foi assumido o valor de cota nula numa estação de referência localizada no município de Itu - SP sem, entretanto, constar qualquer especificação da Referência de Nível (RN) utilizada, ou sua descrição e posição geográfica. Considerando que esse tipo de tratamento inviabiliza a adição de novos dados ao levantamento existente sem introduzir descontinuidades no campo gravitacional resultante, optou-se por efetuar um novo levantamento gravimétrico na mesma região.

Apresenta-se em seguida a metodologia utilizada na obtenção das várias componentes do campo gravimétrico, e a modelagem do complexo em subsuperfície, com geometria tridimensional, a qual permitiu determinar o volume do mesmo.

\section{GEOLOGIA DA ÁREA}

O Complexo Alcalino de Ipanema, com área aflorante de $8 \mathrm{~km}^{2}$, situa-se morfologicamente na Serra de Araçoiaba, uma feição topográfica aproximadamente circular, tendo o ponto culminante aproximadamente $967 \mathrm{~m}$ de altitude, e a média regional cerca de $570 \mathrm{~m}$. A estrutura é composta por rochas alcalinas e seus produtos; nota-se que nas proximidades do complexo, as rochas encaixantes foram soerguidas devido ao alojamento da intrusão alcalina.

A idade do complexo de Ipanema foi calculada pelo método K-Ar em aproximadamente $123 \mathrm{Ma}$ (Amaral et al., 1967) e posteriormente 130,9 \pm 9,5 (Sonoki e Garda, 1988), datando, portanto, do Cretáceo Inferior. Este valor de idade o posiciona quase contemporâneo às rochas alcalinas mais próximas, como por exemplo, Jacupiranga (132 Ma; 129,6 \pm 4,5 a 155,2 \pm 4,6 Ma) e Juquiá (130 Ma; 131,7 —1,6 a 151,1 \pm 7,7 Ma) (Morbidelli et al., 1995; Sonoki e Garda, 1988).

As principais litologias alcalinas reconhecidas (Figura 1), são compostas por glimeritos e shonkinitos (Toledo e Souza, 1991). O glimerito é uma rocha ígnea máfica formada quase que essencialmente por biotita. O shonkinito, um sienito máfico, é composto principalmente por augita e feldspato alcalino, contendo subordinadamente olivina, hornblenda, quartzo (0 - 5\%) e feldspatóides (0 - 10\%). Circundando o glimerito, encontram-se fenitos, rochas oriundas de processos metassomáticos ao redor de intrusões alcalinas (Sørensen, 1974).

As rochas encaixantes são compostas por sedimentos e metassedimentos permocarboníferos do Grupo Tubarão, e pelo embasamento cristalino Pré-Cambriano. O Grupo Tubarão é composto pelas seguintes litologias: tilito, arenito, siltito, folhelho e ritmitos. O embasamento contém quartzitos, filitos, micaxistos, granitos e anfibolitos, sendo que, a norte da manifestação glimerítica, observam-se depósitos autóctones localizados do tipo evaporítico, representados por calcários (Figura 1).

A xistosidade das rochas metassedimentares apresenta em média atitude N50E e os mergulhos são próximos da vertical. Nas proximidades dos afloramentos alcalinos os metassedimentos encontram-se extremamente deformados e fraturados.

O complexo encontra-se alojado na porção limítrofe oriental da Bacia do Paraná. Com base nos resultados gravimétricos de Davino (1965; Figura 2), e considerando a presença de outras manifestações alcalinas localizadas nos municípios de Tatuí e Piedade, e os alinhamentos das intrusões shonkiníticas observadas em dois pequenos 


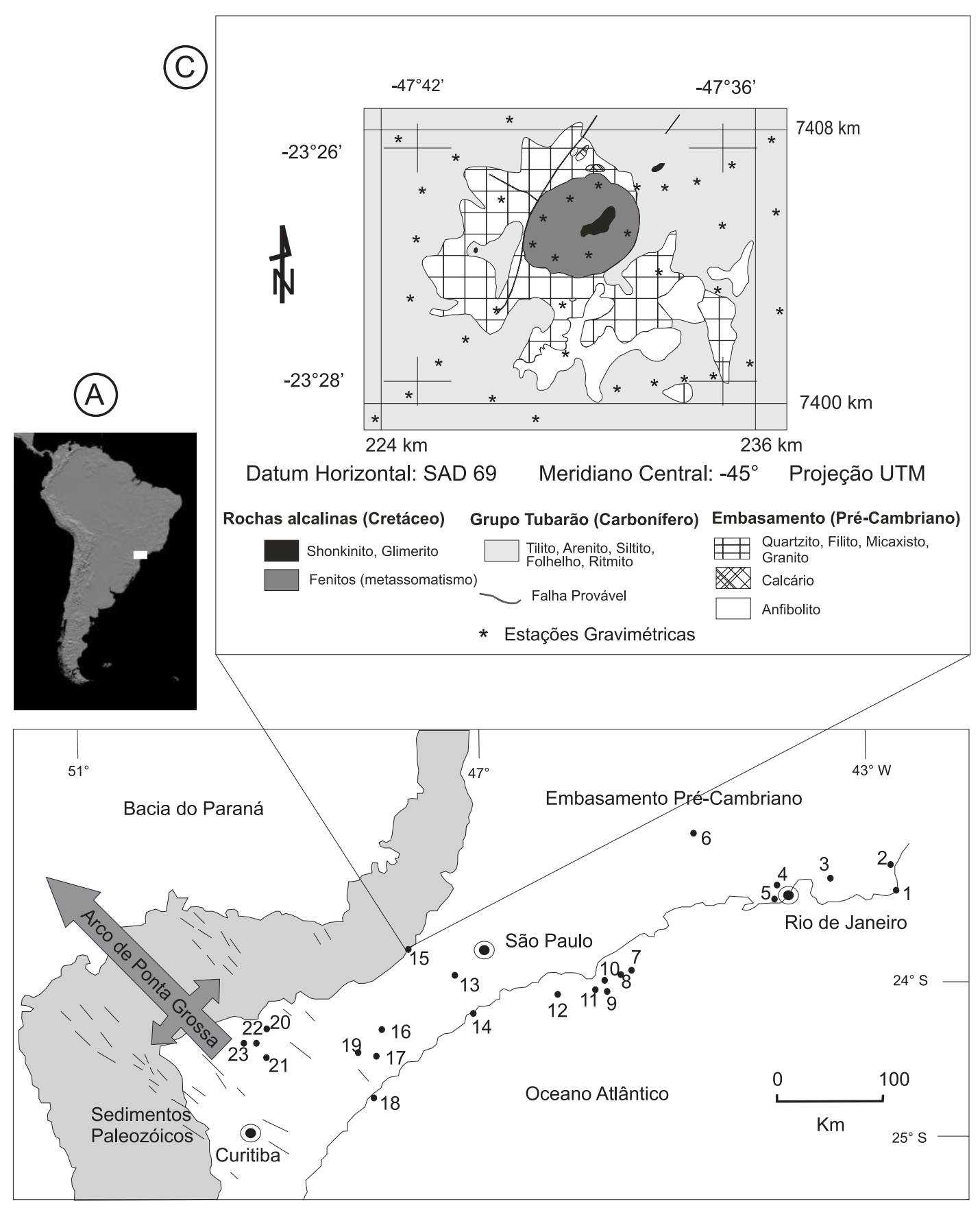

(B)

Figura 1. A) Localização da região de interesse no sudeste brasileiro. B) Detalhe da área onde se insere o Complexo Alcalino de lpanema. Os pontos correspondem à localização das principais intrusões alcalinas conhecidas na Província Serra Negra. 1. Morro de São João; 2. Ilha de São Francisco; 3. Rio Bonito; 4. Tinguá; 5. Pico do Marapicu; 6. Itatiaia; 7. Ilha de Vitória; 8. Ilha de Búzios; 9, 10 e 11 . Ilha de São Sebastião; 12. Ilha do Montão de Trigo; 13. Piedade; 14. Itanhaém; 15. Ipanema; 16. Juquiá; 17. Pariquera-Açu; 18. Cananéia; 19. Jacupiranga; 20. Itapirapuã; 21. Tunas; 22. Banhadão; 23. Barra do Teixeira. As linhas na direção NW-SE representam diques do Lineamento Guapiara e São Jeronimo Curiúva, sobre o Arco de Ponta Grossa. C) Mapa geológico do Complexo Alcalino de Ipanema (extraído de Toledo e Souza, 1991). 


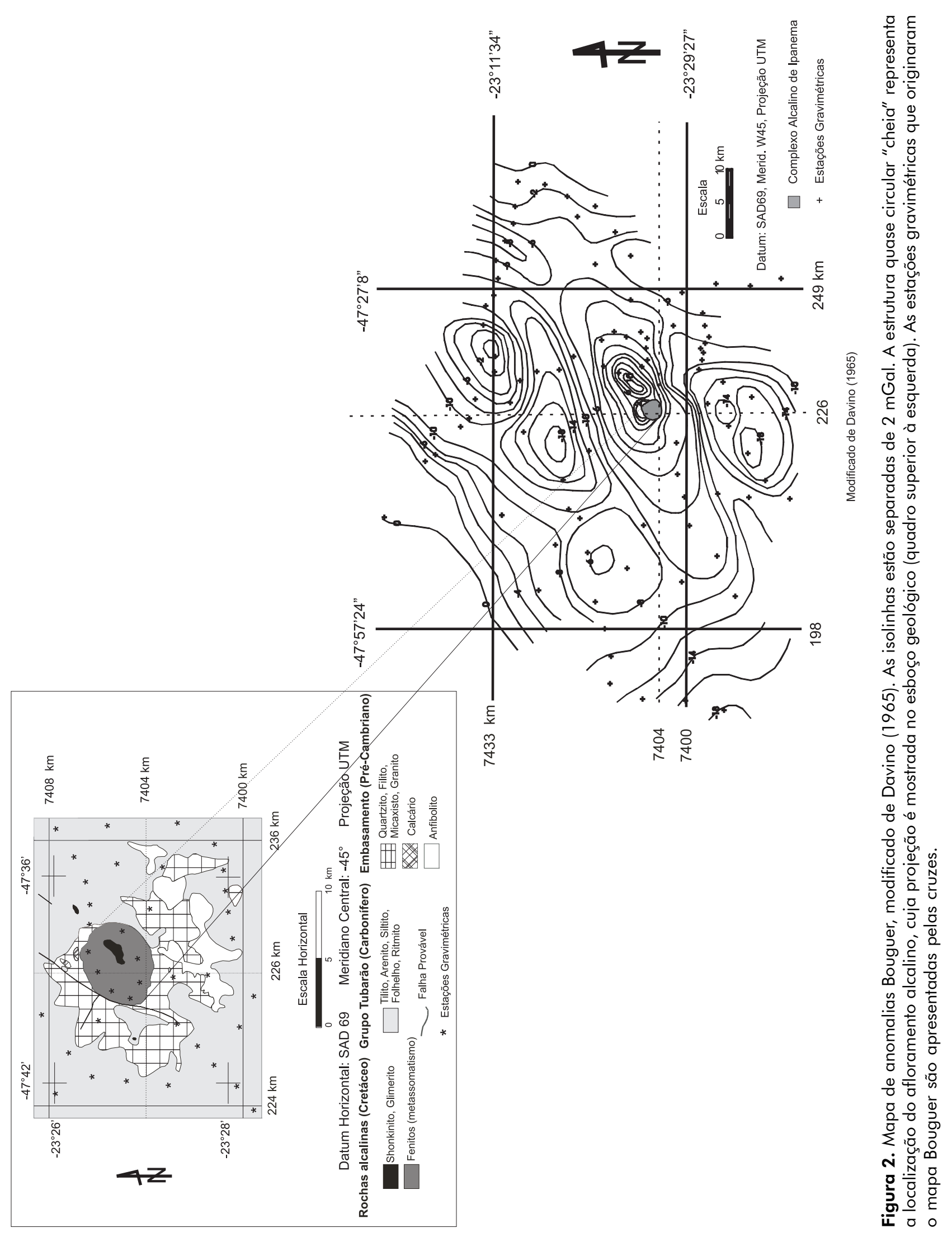


afloramentos na região externa ao fenito, e ao glimerito, Almeida (1983) sugeriu que, durante o Cretáceo, o alojamento do Complexo de Ipanema foi controlado por reativações de falhas pré-silurianas na borda da Bacia do Paraná. Essas falhas são orientadas na direção NE-SW.

Correlações entre o alojamento das rochas alcalinas e as encaixantes foram observadas por Knecht (1930) e Moraes (1938). Segundo esses autores o magma se dispersou nas rochas encaixantes, desenvolvendo corpos tabulares e lenticulares ao longo dos planos de xistosidade, com direção aproximada de N50E, conclusão esta corroborada pela disposição das jazidas de magnetita e apatita em lentes alongadas na direção NE-SW. Evidências do regime tectônico e dos esforços envolvidos na borda da Bacia do Paraná sugerem que o alojamento da intrusão ocorreu num regime de injeção forçada, com metros de rejeito, em conseqüência ao soerguimento do embasamento.

Na imagem da topografia da região (Figura 3), distinguem-se os dois domínios geológicos citados: a Bacia do Paraná (a oeste) e o embasamento (a leste). O afloramento do Complexo Alcalino de Ipanema, observado no domínio da Bacia do Paraná, corresponde à estrutura quase-circular apresentando desníveis topográficos da ordem de $400 \mathrm{~m}$. Na imagem não se identificam lineamentos ou mesmo falhas geológicas nas proximidades do complexo alcalino, enquanto que contatos e falhas transcorrentes na direção NE-SW são observados na porção do embasamento.

\section{METODOLOGIA}

O estudo geofísico, aqui apresentado, concentra-se num levantamento gravimétrico realizado para o presente trabalho, que foi executado especificamente para o estudo do corpo responsável pela anomalia. Para a implantação das estações gravimétricas, foram percorridas estradas, vias secundárias e trilhas.

O cálculo da anomalia de gravidade exige o conhecimento da altitude exata no ponto de medida. No presente levantamento, a medida da altitude de cada estação utilizou o método barométrico com base fixa. Todas as medidas foram referidas à Rede de Nivelamento do IBGE, e a metodologia utilizada é descrita adiante em detalhe.

\section{Levantamento gravimétrico}

Todas as medidas gravimétricas do levantamento aqui descrito foram referidas à Rede Gravimétrica Fundamental Brasileira (RGFB) tomando como referência a EG n 011276 Jundiaí, estação tipo “B”, cota gravimétrica 978613,496 mGal, com incerteza de 0,014 mGal. Uma descrição detalhada da sistemática utilizada encontra-se descrita em Mantovani et al. (2005).
As medidas foram efetuadas em diversas etapas de visita à área de interesse, em função da disponibilidade de equipamentos. Foram alternadamente utilizados dois gravímetros da marca LaCoste e Romberg, modelo G, sendo um com feedback aliod 100 (\#913) e o outro com feedback analógico (\#996). Os valores entre parênteses identificam cada gravímetro pelo seu número de fabricação. As leituras instrumentais no \#913 são fornecidas diretamente em unidades de mGal, enquanto que o \#996 apresenta leituras proporcionais ao mGal, sendo necessária sua transformação através de uma tabela de calibração específica do instrumento. A acurácia do gravímetro \#913 (0,001 mGal) é uma ordem de grandeza superior àquela do \#996 que por sua vez não é inferior a 0,04 mGal.

O levantamento altimétrico utilizou o método barométrico com base fixa. A altitude foi medida em correspondência a cada estação gravimétrica levantada. As bases altimétricas, para áreas num raio inferior a 30 km e desníveis altimétricos inferiores a $200 \mathrm{~m}$, foram transportadas da RN mais próxima, localizada em Indaiatuba-SP (coordenadas geográficas: -23.18, -46.88; cota: 738,5234 m) para o local onde foram efetuadas medidas de altimetria por pressão atmosférica, umidade e temperatura a cada 10 minutos, situada nas coordenadas: -23.26523, -47.29802, sendo a cota transportada de 587,95 m. Simultaneamente, a "estação móvel” efetuava medidas de altitude barométrica, temperatura e umidade, além da leitura no gravímetro em cada nova estação gravimétrica.

Para a base fixa foram utilizados dois altímetros barométricos digitais Air-DB Intellisensor e um altímetro analógico Thommen enquanto que, na estação móvel, foram utilizados dois altímetros Thommen e um altímetro digital portátil Intellisensor. Tanto na base fixa como na estação itinerante, foram feitas medidas de temperatura com o bulbo dos termômetros seco e úmido, para o cálculo da umidade relativa do ar. A distribuição dos erros para esse método de medida tem como desvio padrão aproximadamente $0,5 \mathrm{~m}$, representando menos de $0,2 \mathrm{mGal}$ na medida de g (McLintock et al., 1994). Note-se que a incerteza na medida da altimetria, de muito supera as demais envolvidas no cálculo da propagação de erros. O erro máximo cometido no presente levantamento altimétrico foi de $3 \mathrm{~m}$, resultando ainda num erro inferior a $1 \mathrm{mGal}$, e o erro de fechamento gravimétrico foi inferior a $0,25 \mathrm{mGal}$ na anomalia Bouguer.

No período de novembro de 2003 a janeiro de 2004 foram medidas 410 estações gravimétricas que, adicionadas àquelas do banco de dados disponível junto ao grupo de pesquisa, resultaram num total de 1.527 (Figura 4). Sobre o complexo alcalino foi coberta uma área de 22.305,52 km², com intervalos inferiores a $4 \mathrm{~km}$ entre as estações implantadas. Infelizmente, não foi possível efetuar mais medidas em correspondência ao complexo alcalino diante dos prazos exigidos, incompatíveis com aqueles necessários 
para a obtenção de autorização junto ao Instituto Brasileiro do Meio Ambiente e Recursos Naturais Renováveis (IBAMA), já que a área constitui uma reserva ambiental.

\section{Cálculo das anomalias de gravidade}

O cálculo das anomalias de gravidade em cada ponto de medida leva em consideração as medidas de "g", das derivas estática e dinâmica do gravímetro (Morelli, 1968), da altitude, do efeito de maré sólida (Longman, 1959), e o valor teórico da gravidade calculado para o geóide de referência.

A gravidade de referência é definida pela Fórmula Internacional da Gravidade de 1967:

$$
g_{\text {térico }}=\gamma(\phi)=978031,85 \cdot\left(1+5,278895 \cdot 10^{-3} \operatorname{sen}^{2} \phi+\right.
$$$$
\left.2,3462 \cdot 10^{-5} \operatorname{sen}^{4} \phi\right) \mathrm{mGal}
$$

onde $\varphi$ é a latitude geodésica da estação gravimétrica.

A anomalia Bouguer é calculada pela expressão:

$$
\Delta g_{B}=g_{o b s}-\gamma(\varphi)+0,3086 \cdot h-2 \pi G \rho \cdot h
$$

sendo $G=6,672 \cdot 10^{-11} \mathrm{~m}^{3} \mathrm{~s}^{-2} \mathrm{~kg}^{-1}$ a constante da gravitação universal e $\rho$ a densidade de massa da crosta superior continental $\left(2,65 \mathrm{~g} / \mathrm{cm}^{3}\right)$.

A anomalia Bouguer calculada pela fórmula (2) acima é denominada anomalia Bouguer simples, e não leva em conta o efeito do relevo. No presente levantamento, a correção de relevo não foi aplicada em vista da característica de semidetalhe do levantamento. Na Figura 5 apresenta-se o campo anômalo Bouguer total, calculado para a área que compreende o Complexo Alcalino de Ipanema e litologias vizinhas (eq. 2). Observa-se uma anomalia positiva alongada na direção NE-SW, em acordo com aquela apresentada por Davino (1965). A área da anomalia circunscreve a parte exposta do complexo alcalino, sugerindo a presença de material magmático de mesma origem, em profundidade.

Comparando a topografia com o campo anômalo Bouguer, verifica-se que a posição da Serra de Araçoiaba, onde aflora a maior parte do complexo alcalino, não corresponde ao máximo valor anômalo (Figura 5A). Observase também que o afloramento do shonkinito a NE da rocha fenitizada (Figura 1C), está localizado em correspondência ao máximo valor anômalo da alcalina (Figura 5).

\section{Determinação das componentes regional e residual}

A representação gravimétrica da anomalia Bouguer contém as várias componentes de freqüências características de corpos superficiais com diferentes geometrias, dimensões e densidades que contrastam com as rochas encaixantes, de corpos intermediários e profundos ou de limites de camadas com composições mineralógicas diferentes. Para separar as componentes devidas às várias unidades geológicas, analisase o espectro das freqüências que contribuem para o sinal gravimétrico composto, e utilizam-se filtros numéricos para isolar as componentes de cada faixa de freqüência selecionada. Os filtros que selecionam os maiores comprimentos de onda ("passa baixa”) são geralmente utilizados para determinar a componente gravimétrica regional, ou campo regional, devido a corpos de dimensões da escala crustal ou litosférica.

O campo gravimétrico regional pode ser determinado de várias formas, sendo a mais utilizada a representação polinomial, cujos parâmetros são definidos por ajuste de mínimos quadrados. O grau do polinômio dependerá da geometria, dimensão e disposição espacial dos vários corpos isolados e dos segmentos crustais e litosféricos característicos de cada área.

Muitas vezes, a presença de um corpo com características tridimensionais (3D) marcantes, pode distorcer o campo regional e introduzir componentes devido apenas ao corpo isolado, como se observa no caso em estudo. Essas distorções podem ser eliminadas com a utilização do método do “polinômio robusto” descrito por Beltrão et al. (1991).

Uma maneira alternativa de eliminar essas distorções é o uso do método de omissão (Mantovani et al., em preparação), que calcula o polinômio que melhor se ajusta aos dados após eliminar as estações que definem a anomalia. Este método, aplicado com sucesso em vários exemplos de anomalias com características de corpos com geometria 3-D (Mantovani et al., em preparação), no caso em questão selecionou como representação do campo regional a superfície interpolada por 1.441 pontos de medidas distribuídos pela área na (Figura 4). Sobre o corpo (retângulo menor) foram eliminadas 86 estações. Os dados, excluindo as estações com a componente gravitacional do Complexo Alcalino de Ipanema, foram interpolados através do polinômio robusto de grau 12, com 35 processos iterativos, resultando num desvio padrão final de 3,0 mGal.

As estações eliminadas para fins do cálculo do campo regional estavam circunscritas à isoanômala de $-82 \mathrm{mGal}$, sobre o Complexo Alcalino de Ipanema. A escolha do valor limítrofe para a exclusão dos pontos neste processo levou em consideração vários ensaios que buscaram minimizar a distorção para o menor número de pontos excluídos. O ajuste desses dados utilizou a regressão polinomial dada pela expressão $\mathrm{P}(\mathrm{x}, \mathrm{y})=\mathrm{A}+\mathrm{Bx}+\mathrm{Cy}+\mathrm{Dxy}$, cuja representação foi feita numa malha regular de 350 colunas por 257 linhas (Figura 6). Subtraindo-se a componente regional (Figura 5B) da anomalia total (Figura 5A), obtém-se a componente residual, que representa a contribuição gravimétrica dos corpos mais superficiais, no caso em questão, do Complexo Alcalino de Ipanema (Figura 5C). 


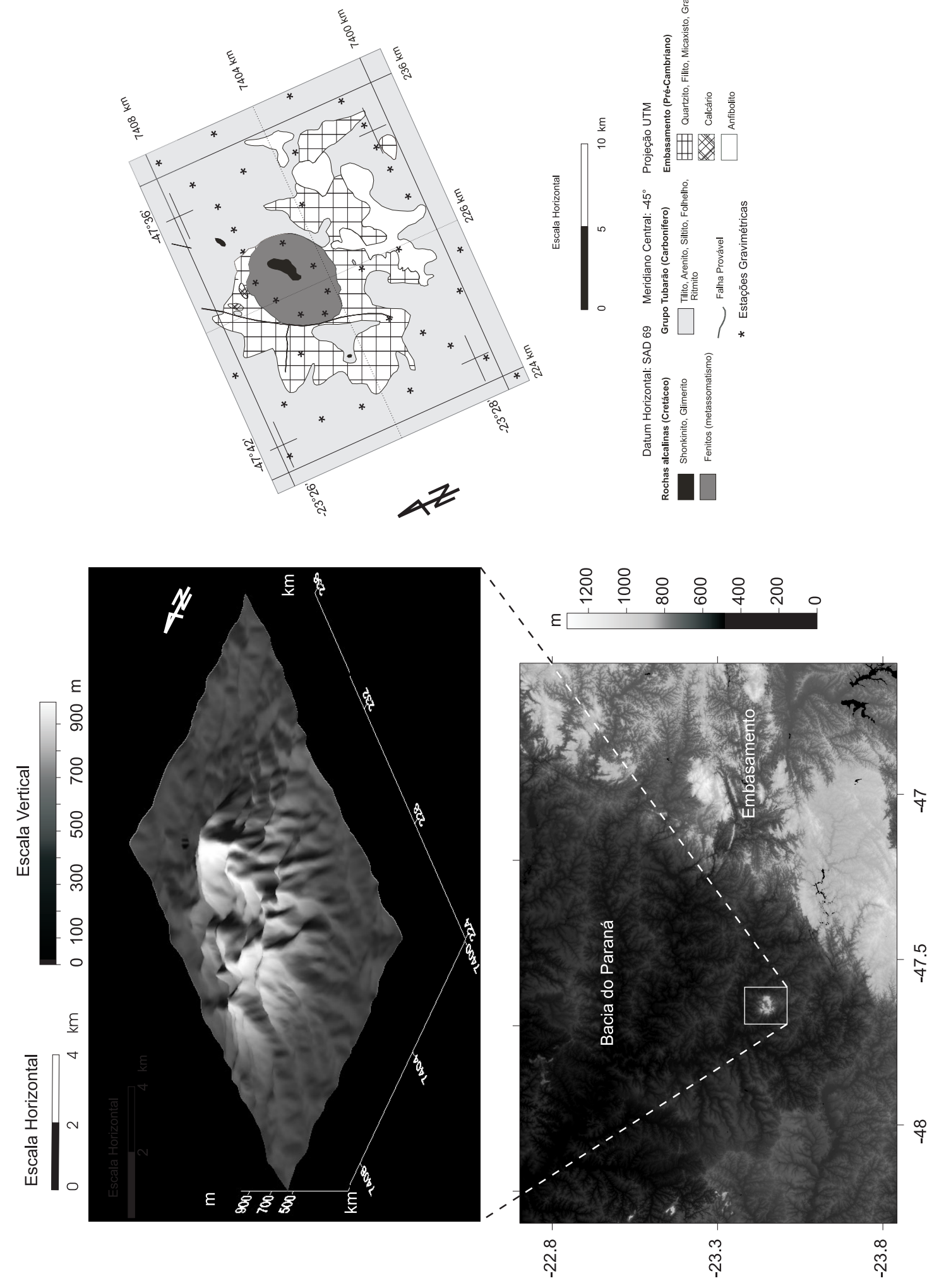

응 웅 웅 훈

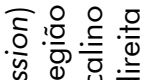

$\stackrel{2}{<} \frac{0}{<}=0$

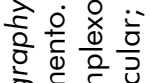

के दे है

응

흘

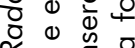

证.

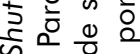

능 등응

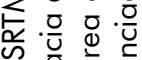

응 웅

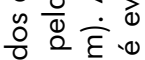

응 0 응

«

ह है $\stackrel{0}{0}$

○ ㅇㅇㅇ

응 色 응

응 $\frac{\mathrm{c}}{\mathrm{E}} \mathrm{g}$

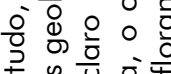

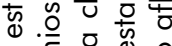

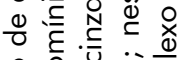

응 응 है

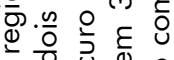

응 \&ै

은

可 $\overline{0}$

응응

응

ह हो 웅응

可证

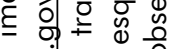

○

ㄴ.

ஸें.

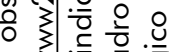

희

岕

정 ह

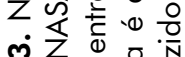

인ㅇㅇㅇㅇㅎㅇ 흥

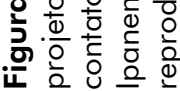


(A)

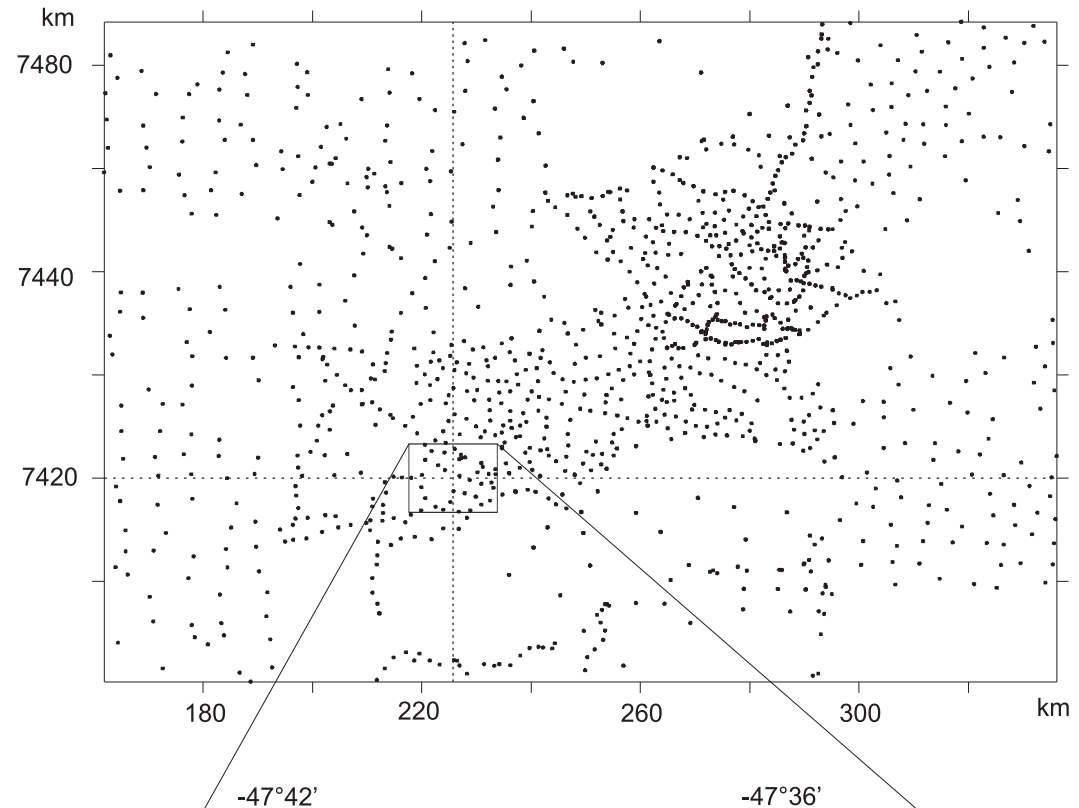

(B)

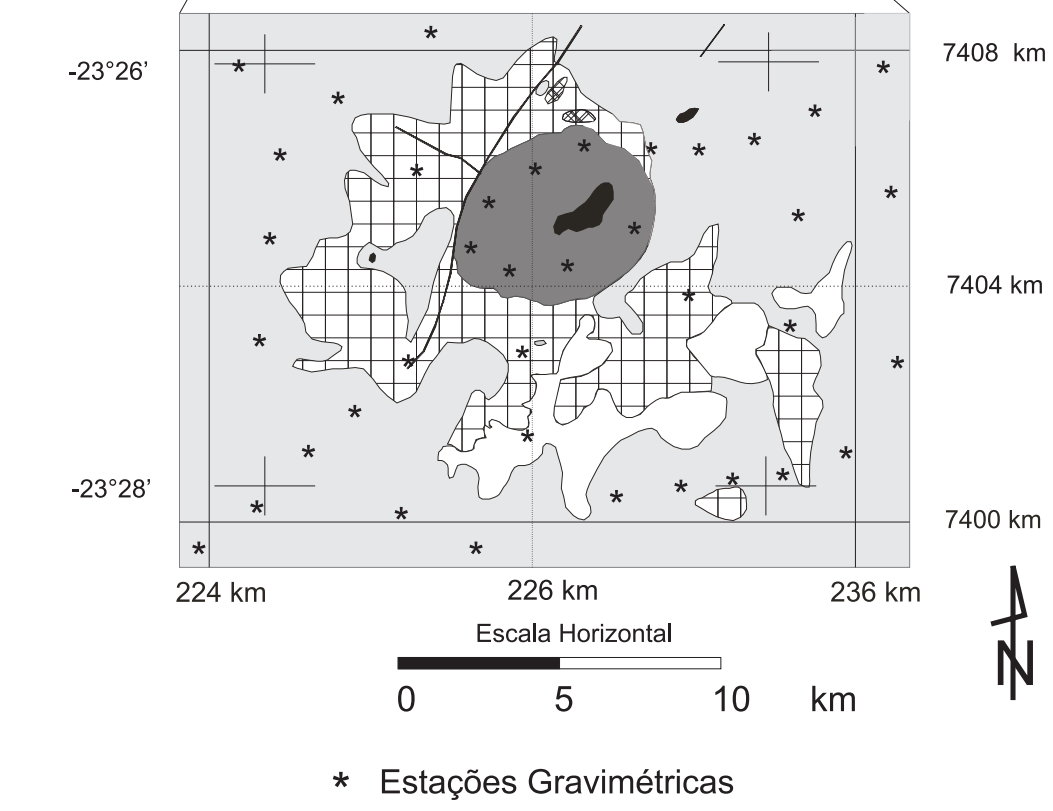

Datum Horizontal: SAD 69 Meridiano Central: $-45^{\circ}$ Projeção UTM

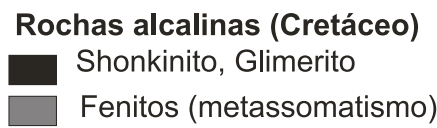

\section{Grupo Tubarão (Carbonífero)}

Fenitos (metassomatismo)

$$
\begin{aligned}
& \square \text { Tilito, Arenito, Siltito, Ritmito, Folhelho } \\
& \sim \text { Falha Provável }
\end{aligned}
$$

Embasamento (Pré-Cambriano)

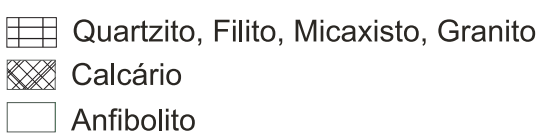

Figura 4. A) Distribuição das estações gravimétricas (pontos). A região selecionada indica a posição do Complexo Alcalino de Ipanema e proximidades. B) Esquema da geologia na região selecionada com a localização das estações. 

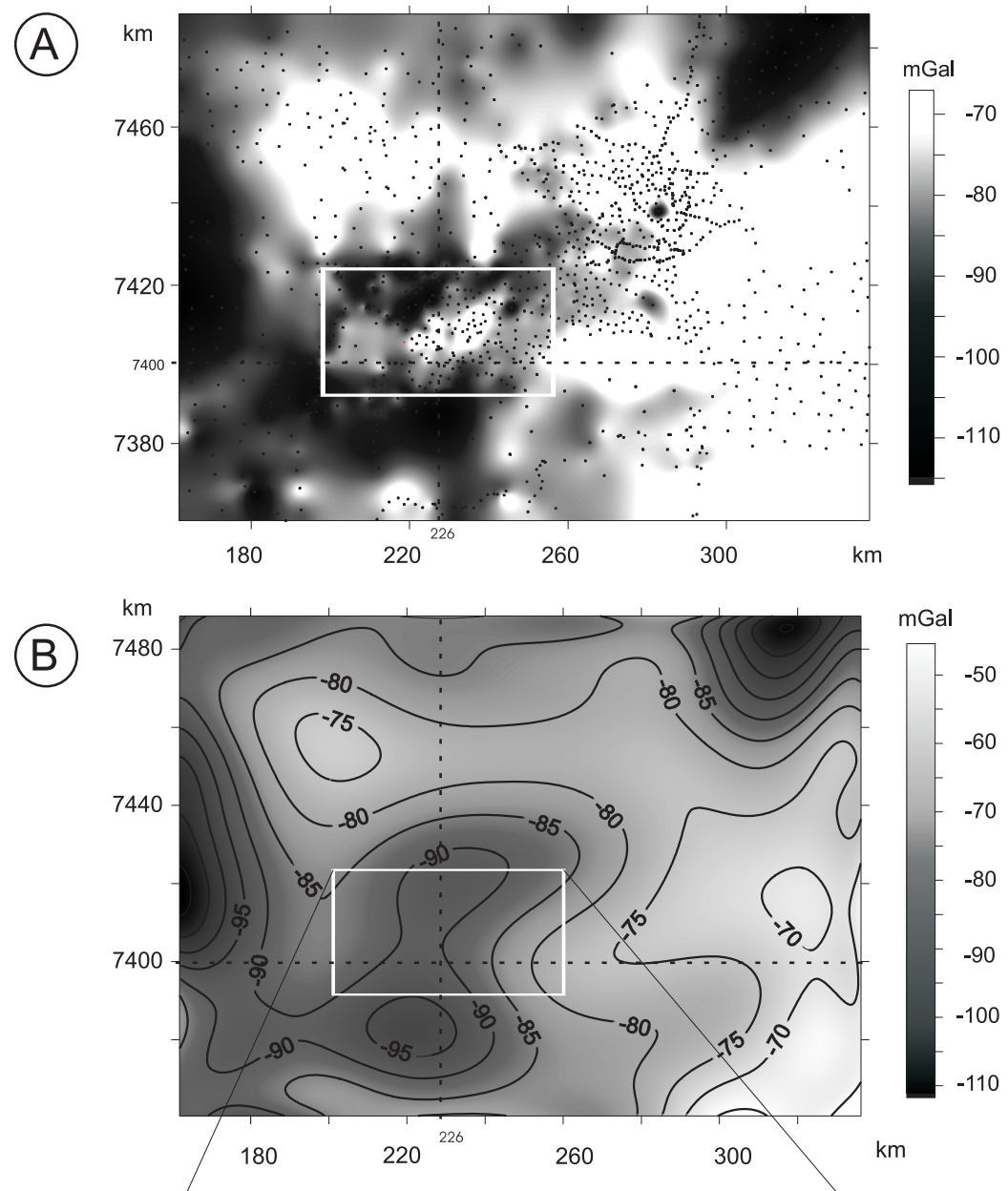

(C)

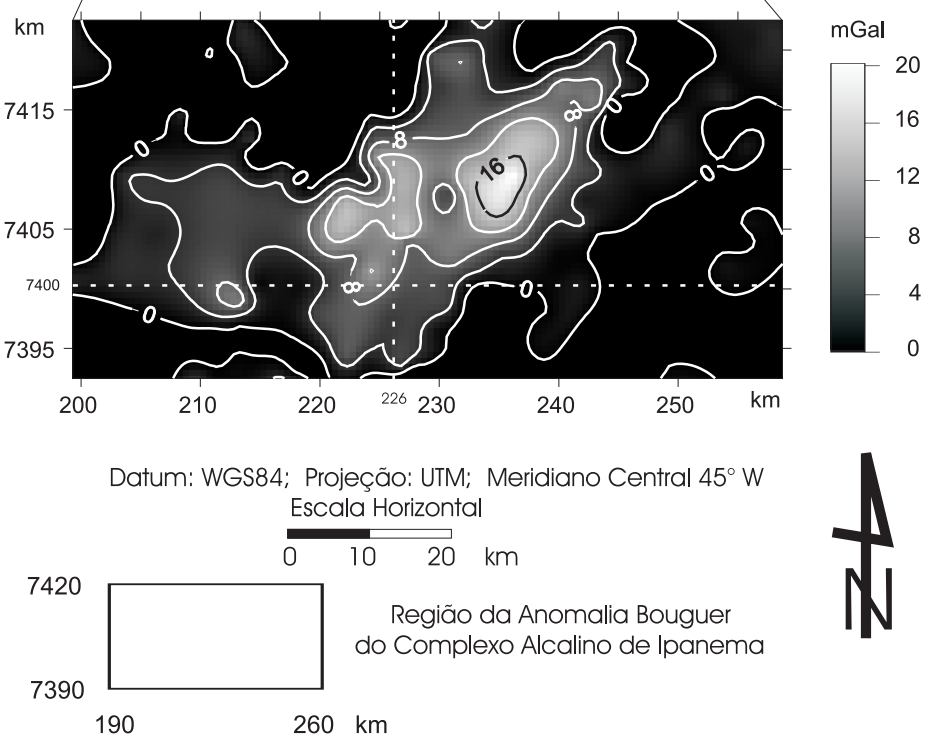

Figura 5. A) Anomalia Bouguer da região de estudo. A anomalia do Complexo Alcalino de Ipanema está indicada no mapa pelo retângulo. Os pontos correspondem às estações de medida. B) Componente regional da anomalia Bouguer. C) Componente residual da anomalia Bouguer do Complexo Alcalino de Ipanema. 


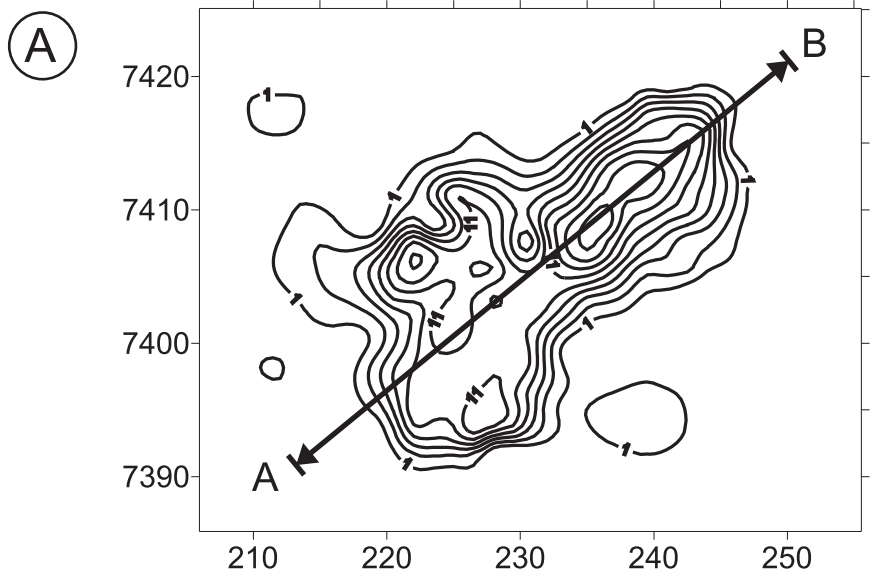

(B)

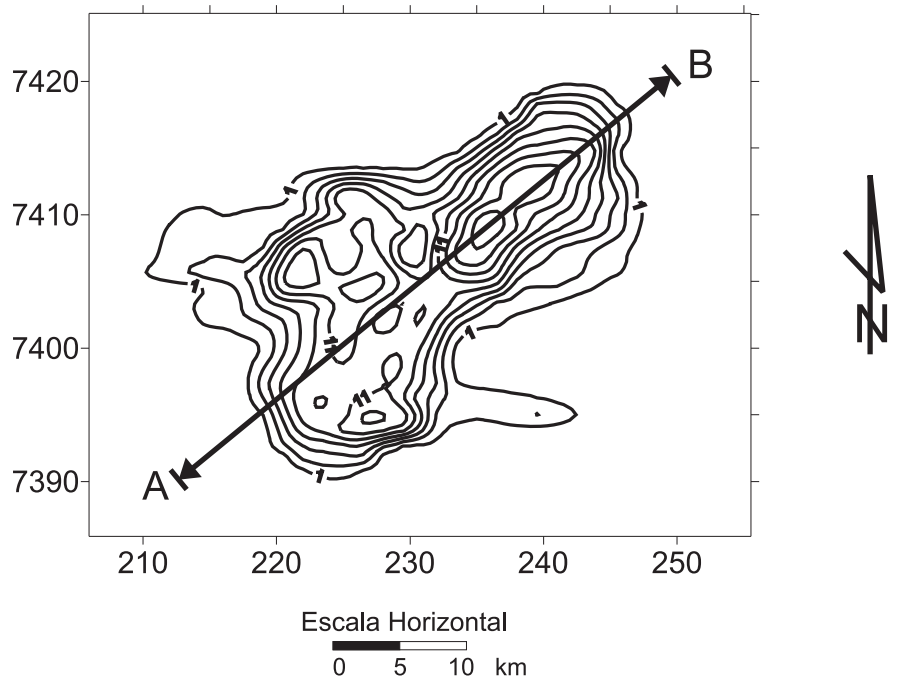

Datum: WGS 84, Projeção: UTM, Meridiano Central $45^{\circ} \mathrm{W}$

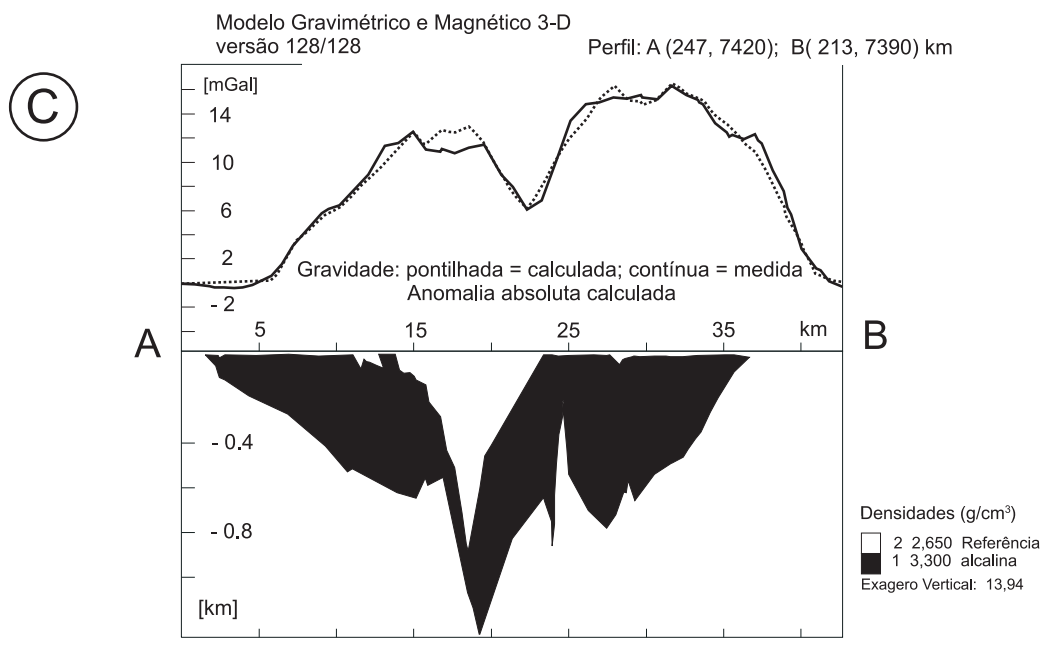

Figura 6. A) Anomalia Bouguer gerada pelo corpo modelado através do programa IGMAS. B) Anomalia Bouguer observada para a mesma área. C) Secção vertical modelada para o perfil AB com geometria 2,5 D. A linha contínua corresponde ao campo observado e a linha pontilhada ao campo gerado pelo modelo. A máxima profundidade verificada é de 1,19 km. 
Inserido no máximo valor anômalo do complexo alcalino verifica-se um pequeno baixo gravimétrico, que coincide com a posição do depósito de calcário. A configuração do campo anômalo total é semelhante àquela já observada por Davino (1965; Figura 2), entretanto com magnitudes diferentes, caracterizadas por dois extremos:

1. os baixos anômalos observados são devido à presença de depósitos sedimentares;

2. os altos gravimétricos afastados da alcalina são associados a intrusões de diabásio e derrames de basalto, notoriamente comuns na borda da bacia.

\section{MODELAGEM DOS DADOS E RESULTADOS}

Uma comparação com complexos alcalinos próximos da área de estudo situa o máximo gravimétrico da anomalia produzida por este Complexo Alcalino de Ipanema (19 mGal) como superior ao de Pariquera Açu (12 mGal; Rugenski et al., 2001) e inferior ao de Juquiá (30 mGal; Slavec et al., 2001). Estes complexos possuem tipos litológicos semelhantes, como exemplo, piroxenito, nefelina sienito, teralito, essexito, malignito e shonkinito entre outros. Em sua maior parte são rochas máficas ultrabásicas e básicas. Essas características são aqui utilizadas para atribuir um contraste de densidade entre o complexo e a encaixante, para fins de modelagem. Outra característica do campo gravitacional de Ipanema é seu alinhamento na direção NE-SW, enquanto que as demais possuem alinhamento na direção NW-SE, direção esta marcante no formato do seu alojamento.

\section{Modelagem 3D}

Para fins de modelagem do complexo, em vista da característica da anomalia bem localizada, optou-se por utilizar programas que permitem modelar um corpo com geometria tridimensional. A anomalia gravimétrica de Ipanema foi modelada com o programa IGMAS (Götze e Lahmeyer, 1988) supondo um contraste de densidade de $0,65 \mathrm{~g} / \mathrm{cm}^{3}$. Isto equivale a considerar, por exemplo, um corpo homogêneo com densidade de $3,30 \mathrm{~g} / \mathrm{cm}^{3}$ e uma rocha encaixante de $2,65 \mathrm{~g} / \mathrm{cm}^{3}$. Considerando as várias litologias citadas, a densidade do corpo intrusivo não se aplica para os glimeritos e shonkinitos; entretanto, esse valor é aqui utilizado para comparação com os modelos das rochas alcalinas vizinhas e que apresentam resposta gravimétrica positiva (Slavec et al., 2001; Rugenski et al., 2001). A densidade medida por Davino (1965) para o shonkinito pórfiro, de $2,79 \mathrm{~g} / \mathrm{cm}^{3}$, é equivalente aos valores de densidade medidos em laboratório para o presente estudo em amostras de shonkinito e malignito de rochas alcalinas de Pariquera Açu, sendo 2,74 $\pm 0,02 \mathrm{~g} / \mathrm{cm}^{3} \mathrm{e}$ $2,81 \pm 0,03 \mathrm{~g} / \mathrm{cm}^{3}$ respectivamente.
Para contrastes de densidades menores, o corpo modelado terá profundidades maiores daquela obtida no modelo (1,19 km). A massa calculada pelo modelo não sofrerá mudanças significativas com essa variação na densidade, uma vez que ao se manter o mesmo ajuste, o volume do corpo aumentará se a massa for mantida constante.

\section{Resultado do modelo tridimensional irregular}

O campo resultante do modelo 3D de formato irregular é observado na Figura 6A. O campo modelado apresenta boa correlação ao campo observado (Figura 6B), tanto nos limites laterais como no máximo valor gravitacional. O perfil AB com orientação NE-SW e limitado entre os pontos A [247; 7420] e B [213; 7390] atravessando a anomalia foi modelado com geometria 2,5 D (secção vertical; Figura 6C); observa-se uma configuração que pode sugerir a presença de dois corpos afins, ou de associações do corpo alcalino com glimerito e shonkinito.

A análise estatística do modelo 3D é visualizada na Figura 7. Na mesma figura apresenta-se a diferença entre os campos observado e modelado em planta, com amplitudes variando entre 2 e $6 \mathrm{mGal}$. Essas diferenças resultam de heterogeneidades litológicas que não foram modeladas e de alterações da encaixante, sendo que apenas $2 \%$ dos dados têm magnitude superior a 2 mGal. A correlação obtida é de $97 \%$ e a média dos resíduos tende a zero mGal. O modelo homogêneo aplicado satisfaz, portanto, as condições de validade.

O volume calculado para a intrusão alcalina de Ipanema para o modelo 3D apresentado resulta em $1,62 \times 10^{3} \mathrm{~km}^{3}$ para um contraste de densidade $\rho=0,35 \mathrm{~g} / \mathrm{cm}^{3}$. Para um valor de densidade atribuído ao complexo alcalino de $3,3 \mathrm{~g} / \mathrm{cm}^{3}$, a massa calculada é de $105,23 \times 10^{12} \mathrm{~kg}$.

A distribuição de massa do modelo projetada em superfície é observada na Figura 8A. A representação da distribuição de profundidades em superfície para o modelo 3D é apresentada sob forma de mapa de isópacas (Figura 8B). A máxima profundidade (1,19 km) encontra-se em correspondência às coordenadas $(235 ; 7410) \mathrm{km}$, ocupando uma área restrita. A profundidade média para a base da intrusão é estimada em $600 \mathrm{~m}$. Observa-se também a separação em planta de dois blocos de rocha, como verificado na secção vertical da Figura 6C.

A semelhança entre as duas distribuições (Figuras 8A e 8B) não é casual, uma vez que a distribuição da massa envolve a distribuição de profundidade associada aos valores de densidade em cada ponto. De outro lado, sua distribuição pode fornecer indicações quanto aos sítios e às direções preferenciais para a injeção dos magmas. No caso em estudo, a distribuição de massa apresenta-se alinhada aproximadamente na direção N60E, que coincide com aquela da borda 


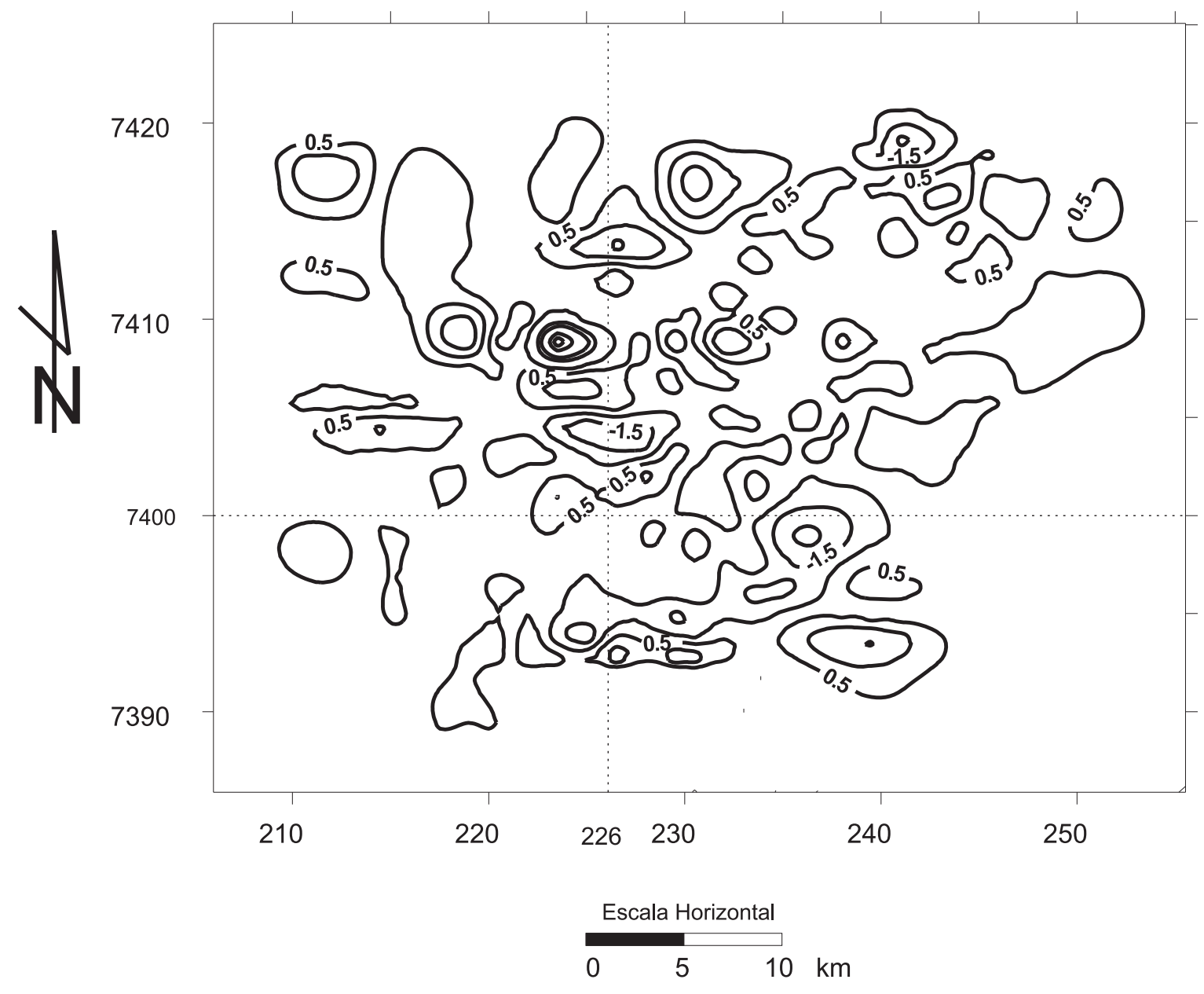

Datum: WGS84, Projeção: UTM, Meridiano Central $45^{\circ} \mathrm{W}$

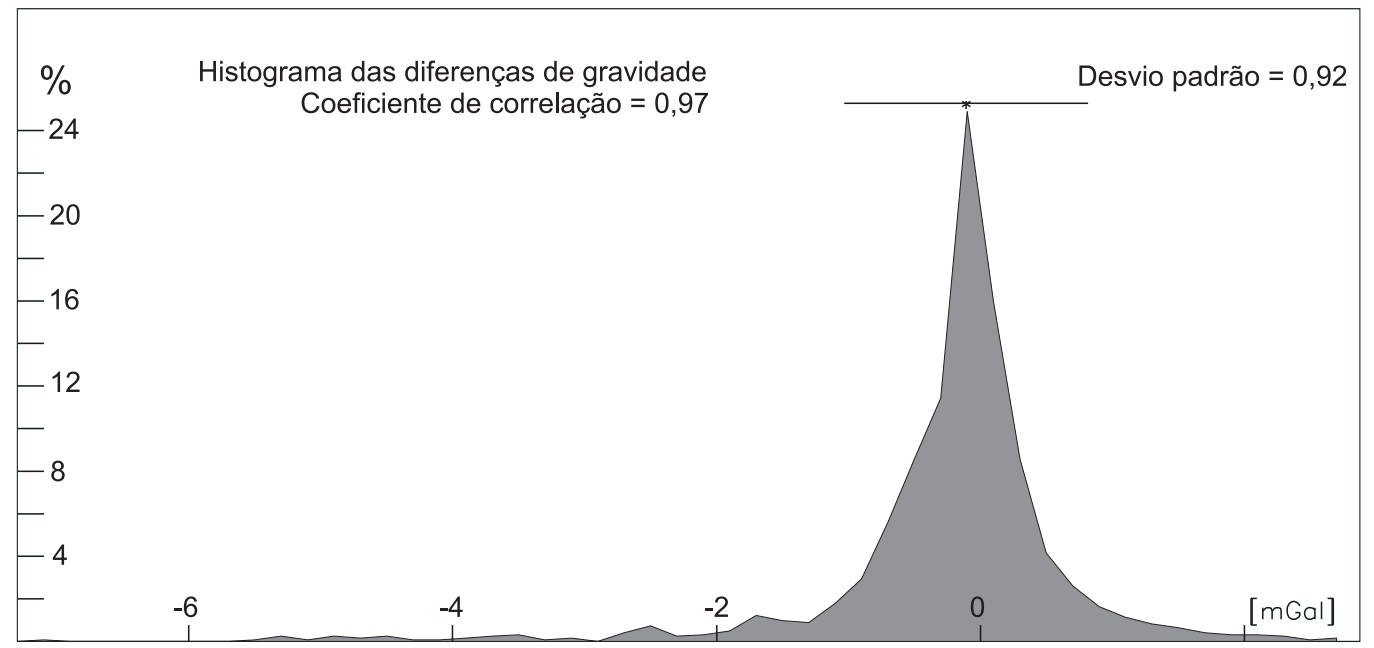

Figura 7. Distribuição em planta dos resíduos e análise estatística do modelo 3D. A correlação entre os campos observados e calculados é de 97\%, com resíduos apresentando uma forte tendência de convergência para zero mGal. 

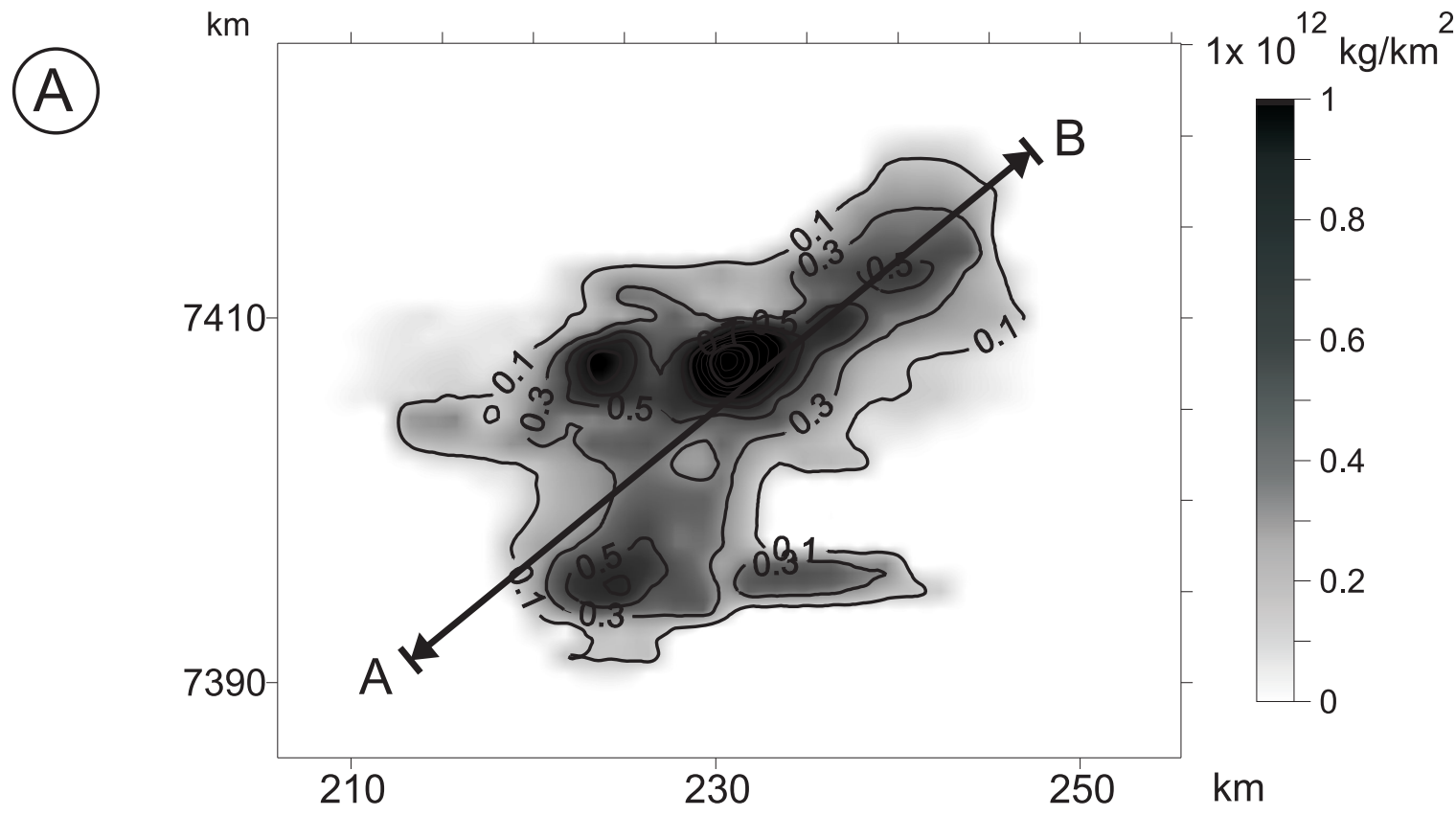

$\mathrm{km}$

(B)

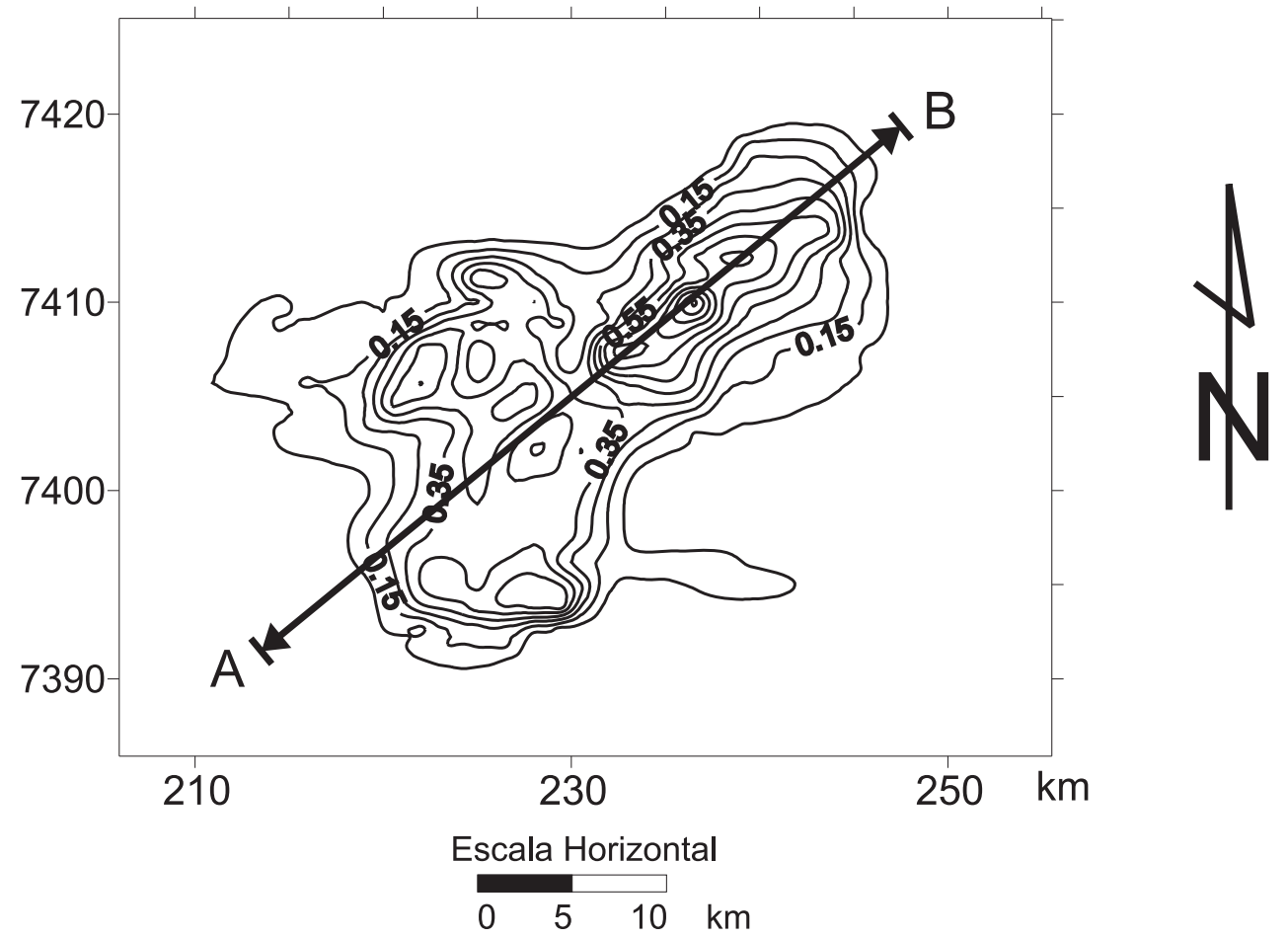

Datum: WGS 84; Projeção: UTM; Meridiano Central $45^{\circ} \mathrm{W}$

Figura 8. A) Distribuição de massa superficial. O eixo central de massa tem direção média de N60E. B) Isópacas do modelo (unidade da profundidade em $\mathrm{km}$ ). 
da Bacia do Paraná na área; aproximadamente na mesma direção (N50E), observa-se a tendência da xistosidade das rochas metassedimentares. Além disso, as jazidas de magnetita e apatita estão alinhadas nessa mesma direção. Essa colinearidade (paralela ou transversal a N60E) pode indicar a direção preferencial para a exploração econômica de minérios associados ao complexo.

A representação espacial do modelo 3D é indicada na Figura 9. Sua geometria em subsuperfície é muito semelhante às demais rochas alcalinas estudadas na área (Slavec et al., 2001; Rugenski et al., 2001; Mantovani et al.,
2005). Nas imagens é visível a presença de diáclases (fraturas, juntas ou falhas no corpo alcalino sem deslocamento relativo das partes), bem como, o seu formato irregular na base, não apresentando um único duto como nos demais casos. O modelo sugere que o alojamento tenha sido por injeção forçada, diante da não existência do duto principal e da sua reduzida profundidade. Essa afirmação condiz com a injeção forçada, uma vez que o duto original não foi preservado ao longo do tempo e o magma se alojou em substratos mais rasos onde os esforços envolvidos são menores.
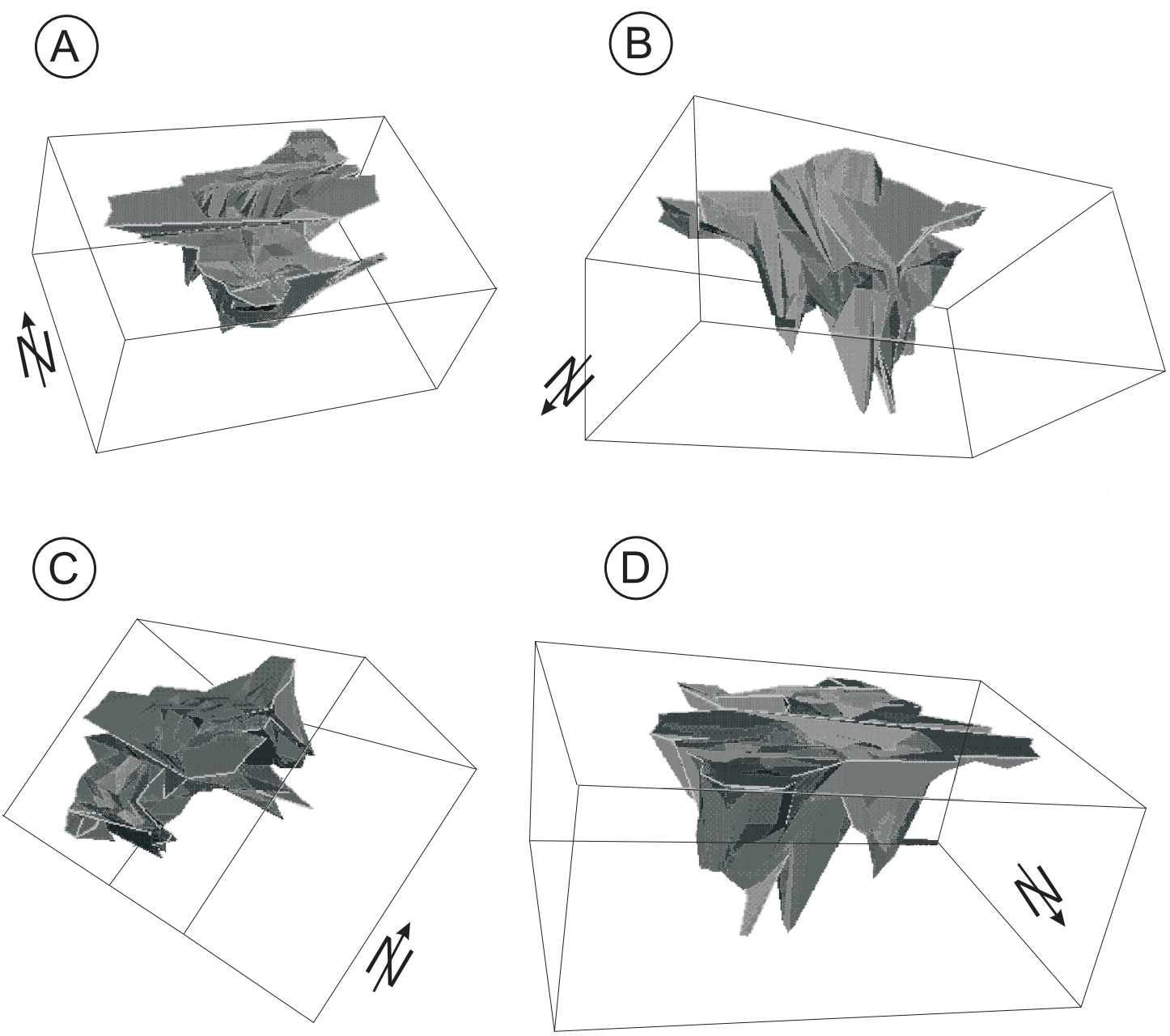

Figura 9. Modelo tridimensional do Complexo Alcalino de Ipanema para uma distribuição homogênea de densidade.

\section{AGRADECIMENTOS}

Os autores agradecem ao Prof. Hajo Göetze e à Dra. Sabina Schmidt por disponibilizarem o Programa IGMAS. À mine- radora Bunge por autorizar a realização de medidas gravimétricas na área sob seu domínio. Aos revisores anônimos pelas sugestões e correções que conduziram à forma final do texto. Os trabalhos foram financiados pelo CNPq-(471426/03). 


\section{REFERÊNCIAS BIBLIOGRÁFICAS}

ALMEIDA F. F. M. Relações tectônicas das Rochas Alcalinas Mesozóicas da Região Meridional da Plataforma Sul-Americana. Revista Brasileira de Geociências, v. 13 p. $139-158,1983$.

AMARAL, G.; BUSHEE, J.; CORDANI, U. G.; KAWASHITA, K.; REYNOLDS, J. H. Potassium-argon ages of alkaline rocks from southern Brazil. Geochimica et Cosmochima Acta, v. 31, p. 117-142. 1967.

BELTRÃO J. F.; SILVA J. B. C.; COSTA J. C. Robust polynomial fitting method for regional gravity estimation. Geophysics, v. 56, n. 1, p. 80-89, 1991.

DAVINO, A. Estudos Geológicos e Geofísicos da Serra de Araçoiaba e Arredores, Estado de São Paulo. Universidade de São Paulo. 1965. 53 p. Tese (Doutorado) Faculdade de Filosofia Letras e Ciências Humanas, Universidade de São Paulo, São Paulo, 1965.

GÖTZE, H. J.; LAHMEYER B. Application of threedimensional interactive modeling in gravity and magnetics (IGMAS), Geophysics, v. 53, n. 8, p. 1096-1108, 1988.

KNECHT, T. Notas Geológicas sobre as Jazidas de Magnetita e Apatita de Ipanema. Secretaria Agricultura Industria e Comercio do Estado de São Paulo, 29 p., 1930.

LONGMAN, I. M. Formulas for computing the tidal accelerations due to the moon and the sun. Journal of Geophysical Research, v. 64, n. 12, p. 2351-2355, 1959.

MANTOVANI, M. S. M.; RUGENSKI, A.; SHUKOWSKY, W. (no prelo) O método de omissão no cálculo do Regional gravimétrico.

MANTOVANI, M. S. M.; SHUKOWSKY, W.; SLAVEC, G. B. O Complexo Alcalino de Juquiá, SP: integração de dados geofísicos. In: SIMPÓSIO SOBRE O CRETÁCEO DO BRASIL, 5., 1999. Rio Claro. Boletim... Rio Claro: UNESP, 1999, p. 219-223.

MANTOVANI, M. S. M.; RUGENSKI, A.; DIOGO, L. A.; SHUKOWSKY, W. Integrated Geophysical Investigation of a possible new alkaline occurrence in SE Brazil. Journal South American Earth Sciences, v. 20, p. 259-266, 2005.

MCLINTOCK, D.; DEREN, E. J.; KRAKIWSKY, E. J. Environment sensitive: DGPS and barometry for seismic surveys. GPS WORLD, v. 6, p. 20-26, 1994.
MORAES, L. J. Jazidas de Apatita de Ipanema, Estado de São Paulo. Boletim DNPM, n. 27, 1-50, 1938.

MORBIDELLI, L.; GOMES, C. B.; BECCALUVA, L.; BROTZU, P.; CONTE, A. M.; RUBERTI, E.; TRAVERSA, G. Mineralogical, petrological and geochemical aspects of alkaline and alkaline-carbonatite associations from Brazil. Earth Science Reviews, v. 39, p. 135-168, 1995.

MORELLI, C. Gravimetria. Udine: Del Bianco, 1968, 575 p.

RUGENSKI, A.; MANTOVANI, M. S. M.; SHUKOWSKY, W. Modelo Gravimétrico do Complexo Alcalino de Pariquera Açu (SP). Revista Brasileira de Geociências, v. 31, n. 3, p. 337-346, 2001.

RUGENSKI, A.; MANTOVANI, M. S. M.; DIOGO, L. A.; SHUKOWSKY, W. Resultados Geofísicos Integrados de um corpo com geometria 3D sem manifestação superficial. Geologia USP. Série Científica, v. 5, n. 1, p. 41-56, 2005.

SLAVEC, G. DE B.; MANTOVANI, M. S. M.; SHUKOWSKY, W. Contribuição ao estudo do Complexo Alcalino Carbonatítico de Juquiá utilizando o método gravimétrico. Revista Brasileira de Geociências, v. 31, n. 2, p. 203-210, 2001.

SLAVEC, G. B.; MANTOVANI, M. S. M.; SHUKOWSKY, W. Estudo geofísico do Maciço Alcalino de Poços de Caldas. Revista Brasileira de Geociências, v. 34, n. 2, p. 275-280, 2004.

SONOKI, I. K.; GARDA, G. M. Idades K-Ar de rochas alcalinas do Brasil meridional e Paraguai oriental: compilação e adaptação às novas constantes de decaimento. Boletim IG-USP. Série Científica, v. 19, p. 63-85, 1988.

SØRENSEN, H. The alkaline rocks. London: New York: John Wiley \& Sons, 1974. 622 p.

TOLEDO, G. M. C.; SOUZA, R. V. Estudo Preliminar daAlteração Intempérica das Rochas Ultramáficas Ricas em Apatita da Mina Gonzaga de Campos, Maciço Alcalino de Ipanema, SP. In: CONGRESSO BRASILEIRODE GEOQUÍMICA, 3., 1991. Extended Abstracts. São Paulo, Sbgq/Sociedade Geológica de Portugal/IG-USP, 1991.p. 91-94.

VIGNERESSE, J. L. Control of Granite Emplacement by Regional Deformation. Tectonophysics, v. 249, n. 3-4, p. 173-186, 1995. 